\title{
Cold surface treatments on fiber-reinforced plastics by pulsed laser
}

\author{
Jana Gebauer'), Gerd Paczkowski'2), Jodok Weixler ${ }^{3)}$, Udo Klotzbach ${ }^{4)}$,
}

1) Fraunhofer Institute for Material and Beam Technology IWS, jana.gebauer@iws.fraunhofer.de, Fraunhofer Institut für Werkstoff- und Strahltechnik IWS, Winterbergstraße 28, 01277 Dresden, Germany

2) Institute of Materials Science and Engineering, gerd.paczkowski@mb.tu-chemnitz.de, University of Technology Chemnitz, Erfenschlager Straße 73, 09125 Chemnitz, Germany

3) Fraunhofer Institute for Material and Beam Technology IWS, jodok.weixler@iws.fraunhofer.de, Fraunhofer Institut für Werkstoff- und Strahltechnik IWS, Winterbergstraße 28, 01277 Dresden, Germany

4) Fraunhofer Institute for Material and Beam Technology IWS, udo.klotzbach@iws.fraunhofer.de, Fraunhofer Institut für Werkstoff- und Strahltechnik IWS, Winterbergstraße 28, 01277 Dresden, Germany

\section{Keywords}

fiber-reinforced plastic, pulsed laser, selective matrix removal, surface pre-treatment, thermal spraying

\begin{abstract}
When producing fiber-reinforced plastic (FRP) suitable for mass production, new technologies have to be developed to overcome existing challenges such as increased efficiency in resource consumption or higher process flexibility. In the past, laser processing has been shown to yield important advantages such as non-contact processing, no tool wear and high design flexibility.

Pulsed laser ablation of FRP offers a promising alternative to state of the art mechanical blasting. The selective matrix removal enables a high potential to improve adhesive bonding, molding processes and coating deposition of lightweight materials, especially FRP-metal or FRP-ceramic hybrids. The resulting increase in surface area exhibits forms lock characteristics and simultaneously provides an expanded interface area. As a result, $40 \%$ higher tensile strength can be reached in pull-off tests compared to a mechanically blasted organic sheet surface, joined by thermal spraying of aluminum on carbon fiber-reinforced epoxy (CFRP).
\end{abstract}

\section{Introduction}

The importance of lightweight materials increases in all aspects of manufacturing, such as the automotive and aerospace industry [1]. Furthermore, FRP will continuously replace metal in more areas because it offers weight reduction and resource efficiency. When metal is being replaced by FRP the surface properties of the metal, such as wear and temperature resistance, are still required. For this reason, FRP substrates get coated by means of thermal spraying. In the print industry metal coated FRP cylinders are already established [2,3]. The current challenge consists of reliably bonding FRP and metal. Due to the high temperature difference between the FRP substrate and the molten coating material, the compound is exposed to thermal stress which leads to spalling. To prevent the spalling of the coating, an adhesion promoting layer should be applied on the substrate before the functional coat is adhered. The schematic construction is illustrated in figure 1. 


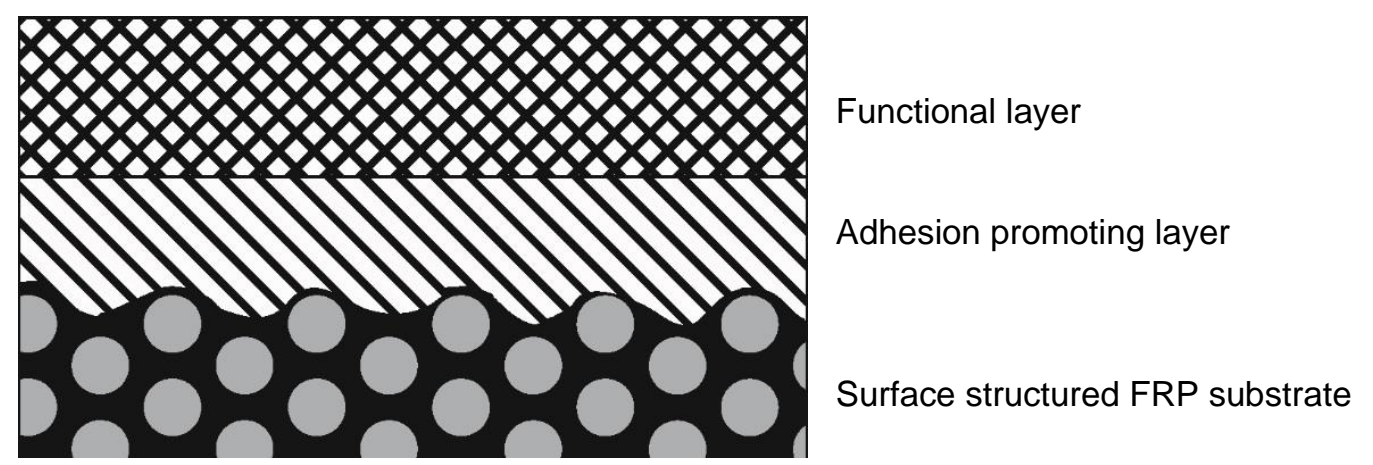

Figure 1: Schematic cross section through a thermal spray coated fiber-reinforced plastic

Furthermore, a surface pre-treatment of the substrate is essential for increased adhesion. Different surface treatments such as sand blasting are well established in the industry. Mechanical blasting increases the roughness of the surface. Note that reinforcing fibers become impaired and protrude from the surface. This is caused by the high acceleration of the blasting material. Broken fibers on the substrate surface can lead to shadowing effects during the thermal spraying process. As a consequence, in industrial production a high reject rate occurs.

By contrast, the selective matrix removal by pulsed laser exposes the fiber reinforcement without damaging them (as shown in figure 2). In addition, the design flexibility of surface structures increases significantly.

The main goal of this work is to increase the adhesive strength of the adhesion promoting layer on CFRP substrates by means of a laser surface pre-treatment, compared to mechanical blasting. The results will be validated by mechanical pull-out tests and cross section analysis.

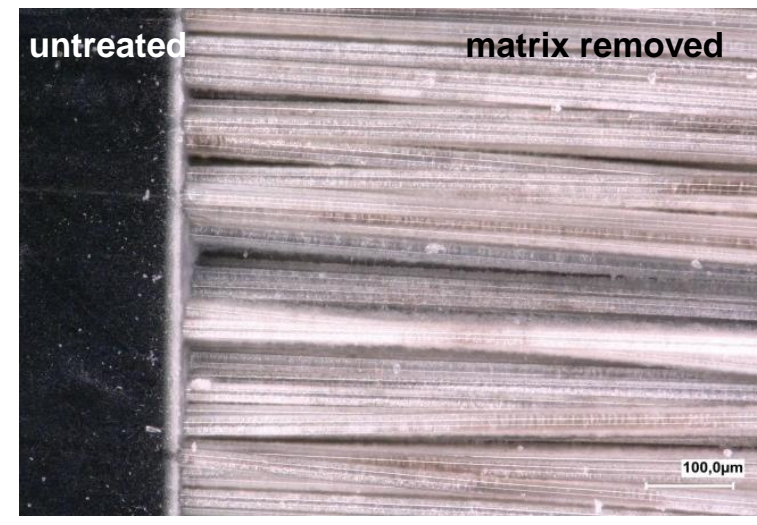

Figure 2: Exemplary image of selective matrix removal on glass fiber-reinforced plastic, compared to an untreated area, top view

\section{Materials and methods}

\subsection{Surface pre-treatment}

For the substrate a carbon fiber-reinforced epoxy is used, consisting of unidirectional ordered layers [0/90/90/0].

The state-of-the-art surface pre-treatment is mechanical blasting with corundum, which will be considered as the reference for this study [4,5].

For the laser treatment, a pulsed Nd:YAG-Laser with the wavelength $355 \mathrm{~nm}$ and an F-Theta Scanner for high beam deflection are used to generate two different surface structures. With the selective matrix removal, the reinforcing fibers become exposed. Moreover, the grid structure ablates the fibers additionally, as is illustrated in figure 3 . 


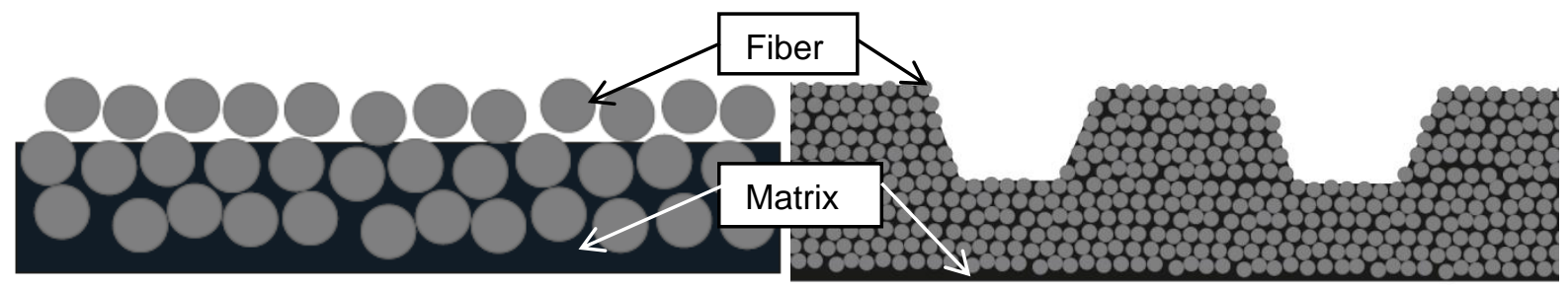

Figure 3: Schematic cross sections of laser structures: selective matrix removal (left), grid structure (right)

The laser process parameters for both surface structures are summarized in table 1.

Table 1 laser processing parameters of surface structures

\begin{tabular}{lllllll}
\hline Structure & Power [W] & $\begin{array}{c}\text { Repetition } \\
\text { number }\end{array}$ & $\begin{array}{c}\text { Scanner } \\
\text { feed rate } \\
{[\mathbf{m m} / \mathbf{s}]}\end{array}$ & $\begin{array}{c}\text { Line } \\
\text { distance } \\
{[\mu \mathrm{m}]}\end{array}$ & $\begin{array}{c}\text { Pulse } \\
\text { length } \\
{[\mathrm{ns}]}\end{array}$ & $\begin{array}{c}\text { Repetition } \\
\text { rate }[\mathrm{kHz}]\end{array}$ \\
\hline $\begin{array}{l}\text { Selective matrix } \\
\text { removal }\end{array}$ & 6,5 & 5 & 1400 & 40 & 35 & 90 \\
\begin{tabular}{l} 
Grid structure \\
\hline
\end{tabular} & 21 & 4 & 500 & 400 & & \\
\hline
\end{tabular}

\subsection{Thermal spraying}

An adhesion promoting layer is applied by wire flame spraying. The coating material is an aluminum wire. An effective atomization of the continuously melting wire materials is achieved by compressed air, as illustrated in figure 4.

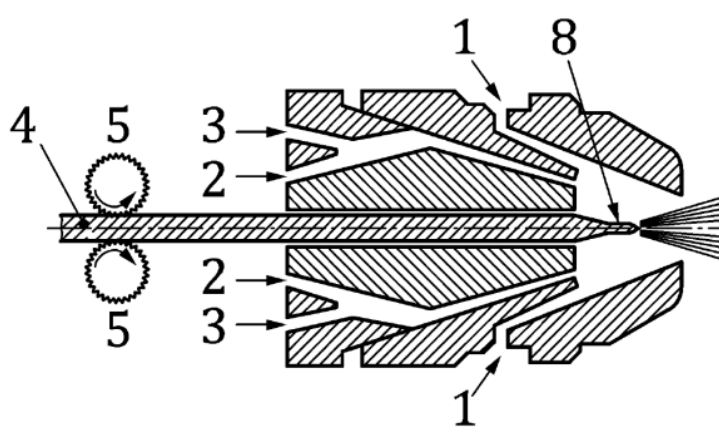

Figure 4: Schematic process of wire flame spraying [6]

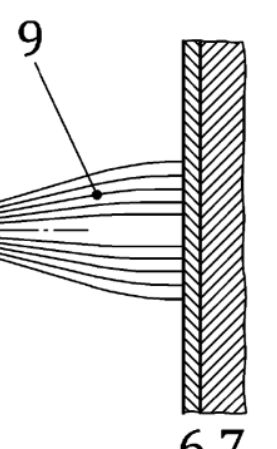

67

The thermal spraying parameters are summarized in table 2 .

Table 2 processing parameters of wire flame spraying

\begin{tabular}{cccccc}
\hline $\begin{array}{c}\text { Repetition } \\
\text { number }\end{array}$ & $\begin{array}{c}\text { Current } \\
{[\mathrm{A}]}\end{array}$ & $\begin{array}{c}\text { Feed rate } \\
{[\mathrm{m} / \mathrm{s}]}\end{array}$ & $\begin{array}{c}\text { Spraying } \\
\text { distance } \\
{[\mathrm{mm}]}\end{array}$ & $\begin{array}{c}\text { Oxygen } \\
\text { flow } \\
{[\mathrm{I} / \mathrm{min}]}\end{array}$ & $\begin{array}{c}\text { Electrical } \\
\text { potential } \\
{[\mathrm{V}]}\end{array}$ \\
\hline 3 & 100 & 2 & 200 & 40 & 35 \\
\hline
\end{tabular}




\subsection{Testing}

According to DIN EN ISO 14916, the adhesive pull strength is determined by a pull off test in a tension and pressure testing machine with a feed rate of $1 \mathrm{~mm} / \mathrm{min}$. Each surface structure is verified by six circular CFRP specimens, which measure $25 \mathrm{~mm}$ in diameter. The test setup is visualized in figure 5.

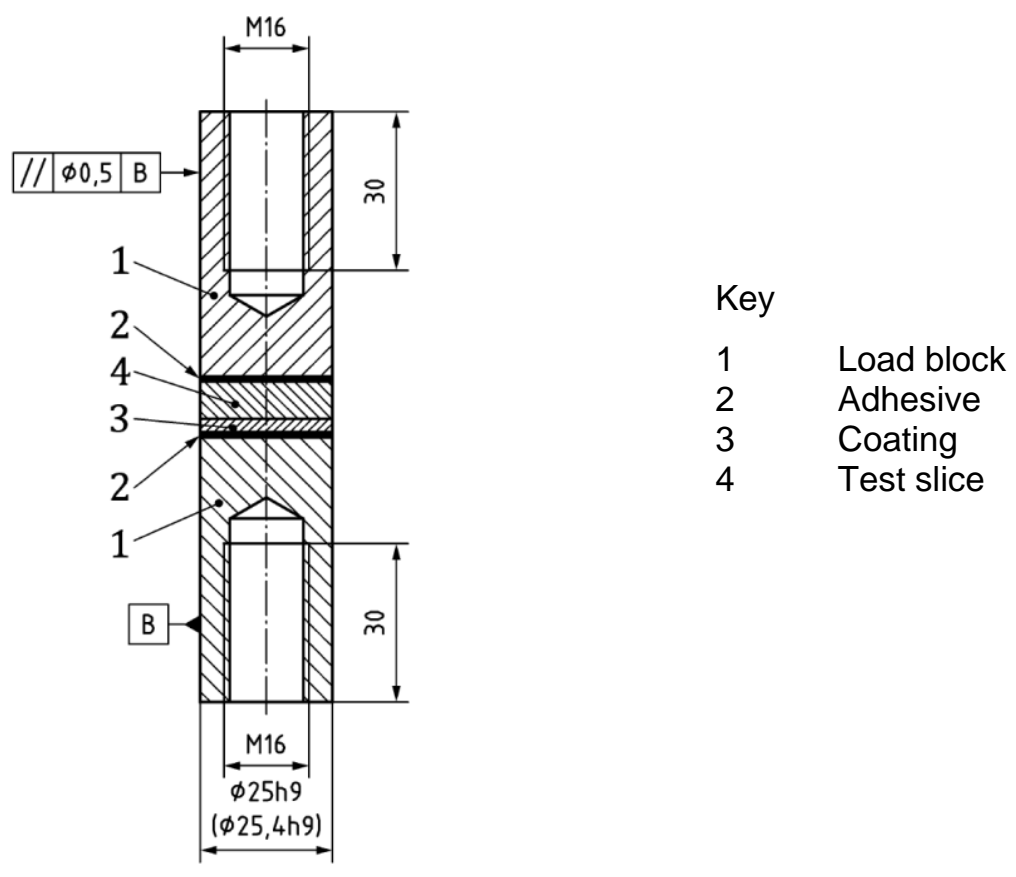

Figure 5: Test setup for pull-out test, all dimensions in $\mathrm{mm}$ [7]

The results are investigated by optical measurements, which are executed in cross sections of the coated substrates in fiber direction as well as perpendicular to it. Therefore, important characteristics such as the penetration of the coating material into the substrate and the damage of the substrate by surface pre-treatment can be determined.

\section{Results}

\subsection{Surface structures}

The mechanically blasted substrate in figure 6 shows a rough surface with broken fibers and matrix particles sticking out of it. 


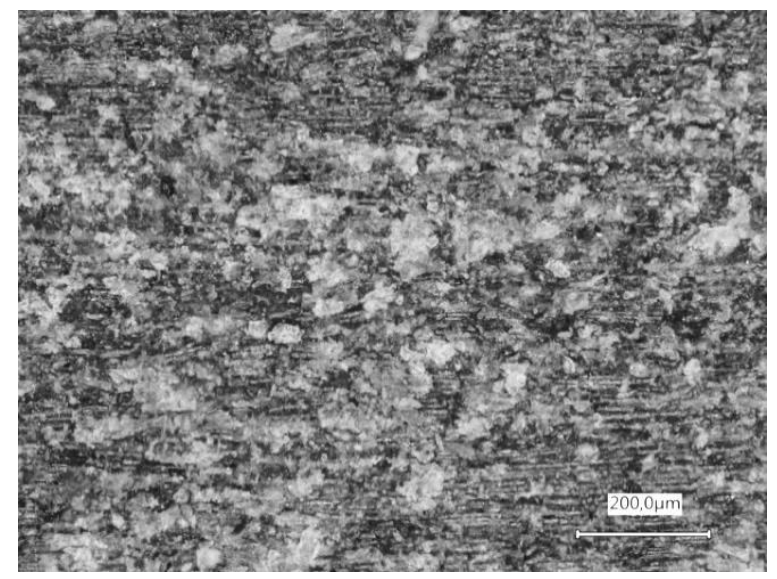

Figure 6: Top view of mechanically blasted CFRP

The structure of a selective matrix removal (figure 7 a) shows an uneven surface and the fibers are not damaged. This structure enlarges the effective surface area significantly. Several near-surface fibers are free of polymer matrix and provide a form fit with the coating. A more effective surface area is reached by the grid structure with an aspect ratio of $3: 2$. As seen in figure $7 \mathrm{~b}$, the fibers on top of the squares are still enveloped by matrix, unlike the edge area and the structure trenches.

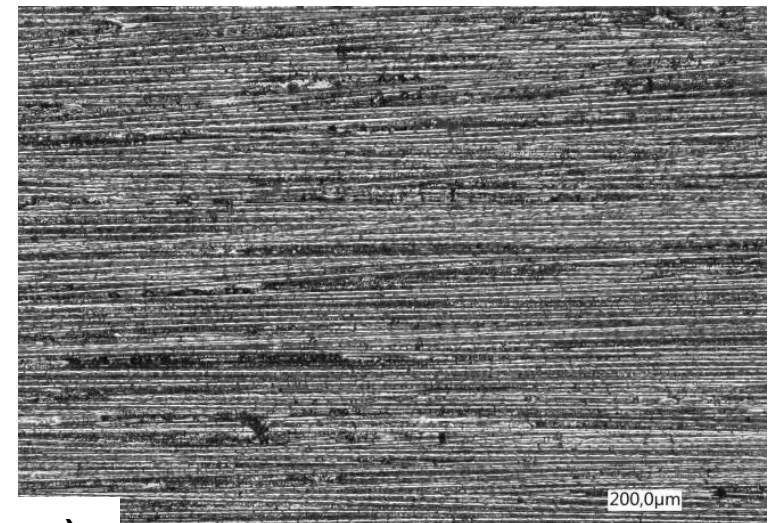

a)

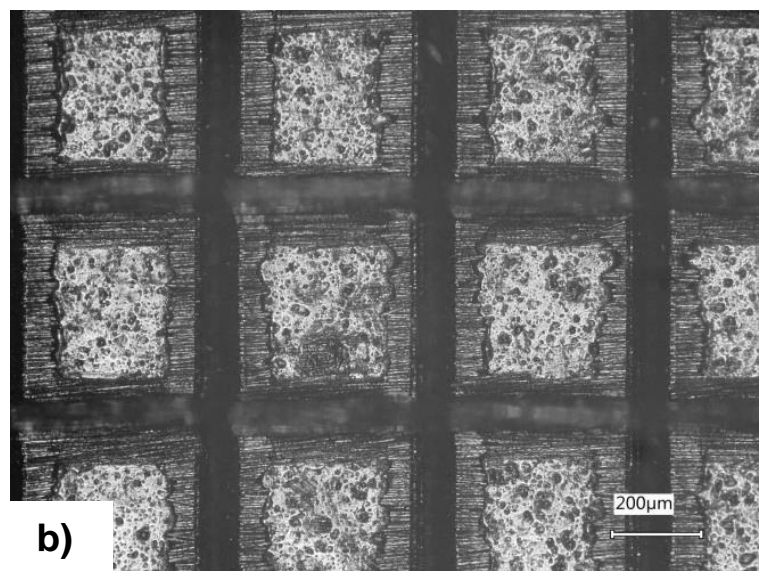

Figure 7: Top view of surface structures: a) selective matrix removal and b) grid structure

On one hand, with the grid structure, a conscious impairment of the fiber reinforcement is generated, until it reaches an average depth of $150 \mu \mathrm{m}$. In this regard, the laser ablation is dependent on the fiber direction. In case of identical laser process parameters, the structure depth parallel to the fibers is $180 \mu \mathrm{m}( \pm 20 \mu \mathrm{m})$ and perpendicular to them $120 \mu \mathrm{m}( \pm 15 \mu \mathrm{m})$. On the other hand, the grid structure offers an enlarged interface area and the matrix free fibers along the structured lines enable a form fit.

\subsection{Mechanical strength}

The laser structuring is performed to investigate its influence on the adhesive strength of metal coating the FRP, compared to mechanical blasting. The results of the pull-off test are presented in figure 8. 


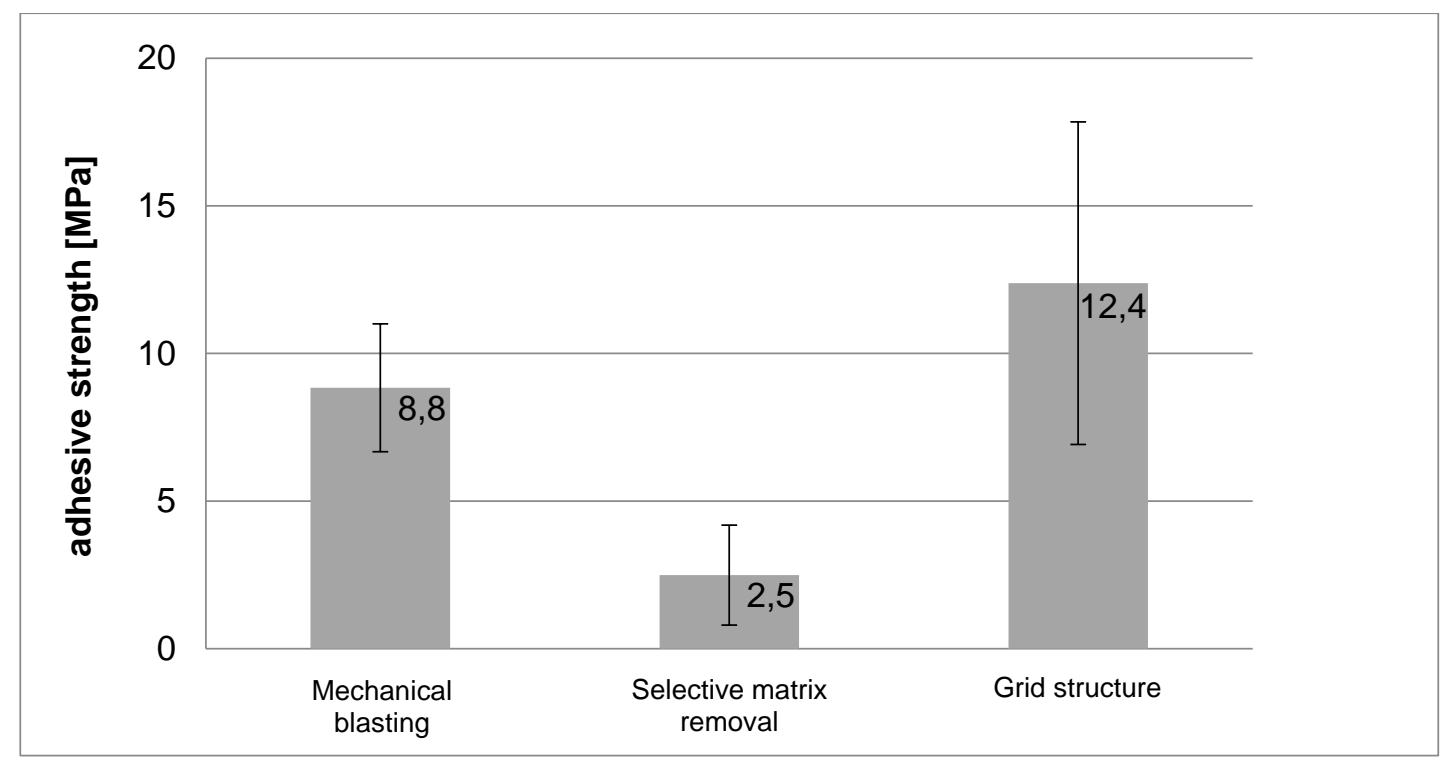

Figure 8: Tensile strength depending on surface structure

With state-of-the-art mechanical blasting, the adhesive strength with a reference value of $8,8 \mathrm{MPa}$ is determined. Against expectation, the selective matrix removal structure in CRFP reaches an adhesive strength of one third of the reference value, with a standard deviation of $68 \%$. The reference value of mechanical blasting is exceeded by that of the grid structure. With this laser pre-treatment an adhesive strength of $12,4 \mathrm{MPa}$ is obtained, although the standard deviation of $5,5 \mathrm{MPa}$ is high.

\subsection{Cross section analysis}

After the thermal spraying of aluminum onto the CFRP substrate, samples of all three different surface pretreatments are analyzed in cross sections. Microscopic images show the covering of exposed fibers with coating material in fiber direction in detail. A perpendicular investigation reveals damaged fibers near the surface.

All cross sections in figure 9 to figure 11 show an uneven thickness of the porous aluminum coating.

As can be seen in figure $9 \mathrm{a}$, single fibers are completely surrounded by coating material. In figure $9 \mathrm{~b}$ it is visible that these enclosed fibers are broken fiber fragments (highlighted by red circle).
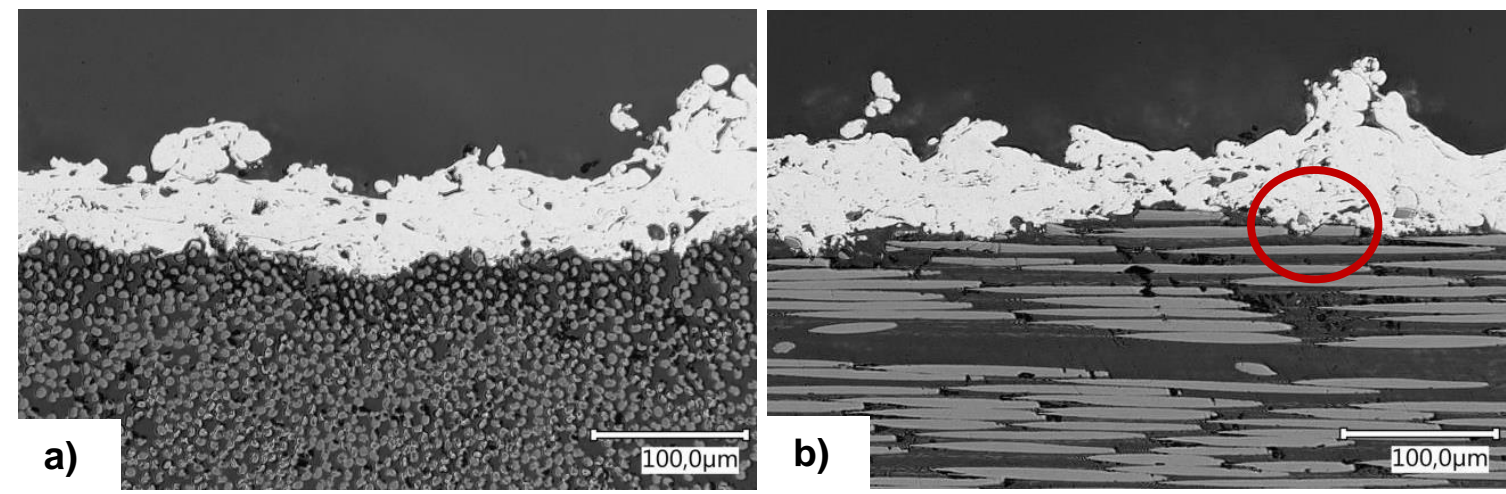

Figure 9: Cross section of aluminum coated, mechanical blasted CFRP a) in fiber direction and b) perpendicular to fiber direction

In the cross sections, especially in fiber direction in figure $10 \mathrm{a}$, an interrupted coating is shown. Furthermore in figure $10 \mathrm{~b}$ air pockets were discovered, which are highlighted by red circles. 

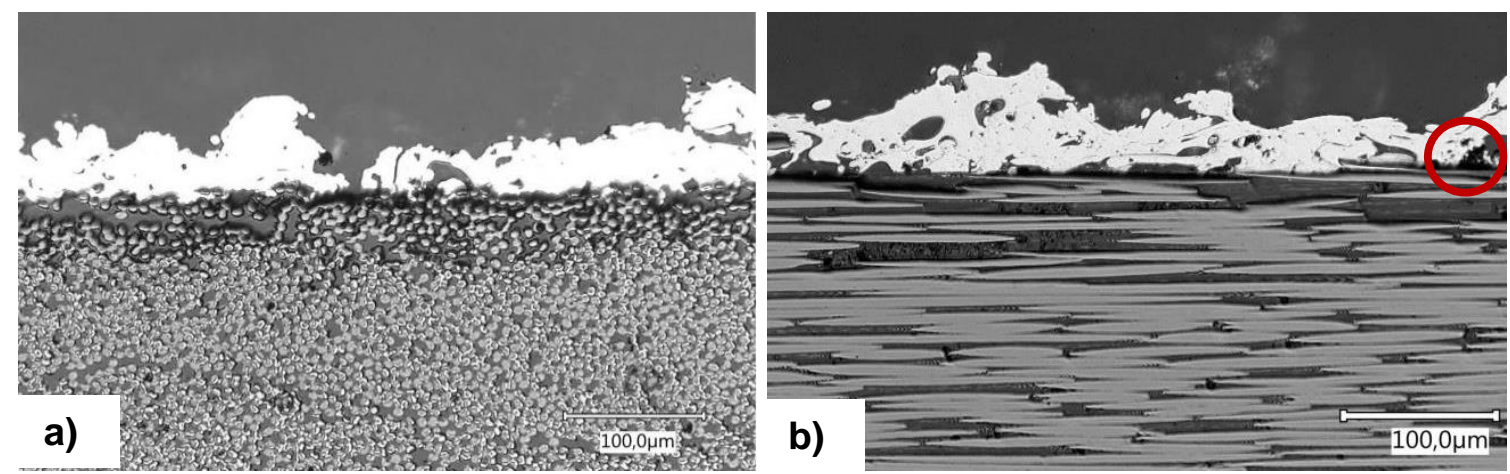

Figure 10: Cross section of aluminum coated, selective matrix removed CFRP a) in fiber direction and b) perpendicular to fiber direction

In between the structure trenches, the matrix covers surface-near fibers, highlighted by the red ellipse in figure $11 \mathrm{a}$. In these areas the coating layer is interrupted due to insufficient coating adhesion. Within the patterned sections the coating material reaches between surface-near fibers and encloses them as seen in figures $11 \mathrm{a}$ and $\mathrm{b}$, accentuated by the blue doted circles.
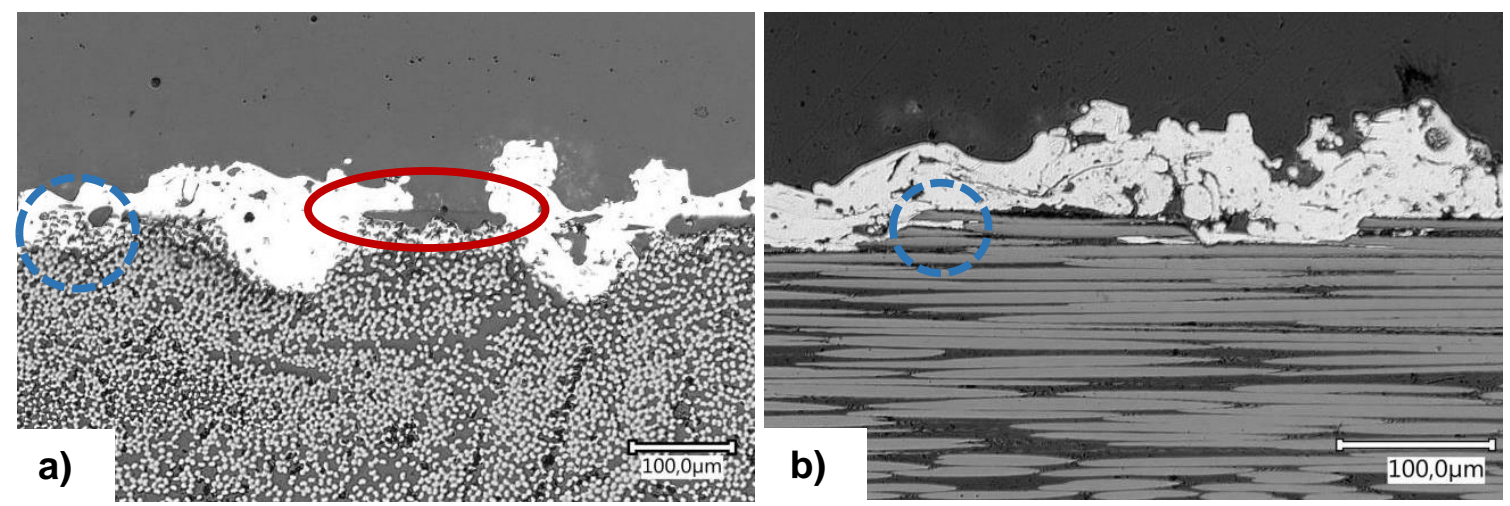

Figure 11: Cross section of aluminum coated, grid structured CFRP a) in fiber direction and b) perpendicular to fiber direction

\section{Discussion and conclusion}

All structure conditions exhibit a thin, porous aluminum coating as an adhesion promoting layer for a subsequent deposition of a functional layer. The porosity is crucial to reduce the heat conduction during the coating process of the functional coating. Imperfections in the adhesion promoting layer can lead to thermal damage of the substrate material and in consequence to defects within the functional layer. The reason for the discontinuity depends on the surface structure and will be discussed below. Moreover, the porosity leads to a high standard deviation in the pull-off tests.

The main disadvantage of mechanical blasting is fiber fragmentation, which locally prevents the adhesion of the coating material and entails a weakening of the composite. Furthermore, a high risk of deposits of the blasting material in the substrate is given. The influence of the discovered imperfections as well as remaining matrix particles and fiber fragments imply an adhesive strength of 8,8 MPa with a standard deviation of $25 \%$.

An inhomogeneous surface of the FRP leads to an interrupted coating of the selective matrix removed specimens. Additionally, the specimen geometry is unsuitable for the matrix removal samples, because the fibers become exposed over the complete specimen length. These weaknesses lead to a lowered average adhesive strength of 2,5 MPa, compared to mechanical blasting. The high standard deviation of $1,7 \mathrm{MPa}$ arises from the inhomogeneous coating quality. 
The highest adhesive strength of $12,4 \mathrm{MPa}$ is achieved by the grid structured CFRP substrates. Several aluminum coated fibers in the grid structured substrate enable a form fit by means of undercut areas. However, the coating layer is interrupted occasionally, which is caused by the matrix agglomeration between the structure trenches. The different structure depths result from the anisotropy of the material, which is caused by the higher heat conduction alongside the carbon fiber, compared to perpendicular to it [1]. As a result, the laser treatment in fiber direction leads to a deeper material removal in comparison to the perpendicular direction. To achieve a homogeneous structure depth, the laser process parameters should be adapted according to the fiber orientation. Alternatively, the grid structure could be orientated $\pm 45^{\circ}$ to the fibers. Additionally, the distance of the structure trenches of the grid structure is $400 \mu \mathrm{m}$. The untreated areas still exhibit original matrix. It is known that untreated surfaces prevent bonding of the coating material. However, the coating is inhomogeneous and the standard deviation is high. Even with the observed imperfections the adhesive strength is increased by $40 \%$ by laser surface patterning compared to mechanical blasting.

In conclusion, the first investigative study shows a high research potential. Further investigations will deal with decreasing the structure trench distance to increase the adhesive strength associated with a lower standard division. Moreover, the aspect ratio of the grid structure is going to be optimized concerning the thermal spraying process. In order to ensure the results and their reproducibility, a larger number of samples are necessary for further research.

\section{References}

[1] Schürmann, H.: Konstruieren mit Faser-Kunststoff-Verbunden. Berlin, Heidelberg: SpringerVerlag, 2006.

[2] Steffens, C.; Bauder, V.: Verfahren zum Herstellen eines beschichteten Bauteils und beschichtetes Bauteil. German Patent Application. DE102013109661A1, 2015.

[3] Habenicht, H.: Verfahren zum Beschichten eines faserverstärkten Kunststoffkörpers. German Patent Application DE4116641A1, 1992.

[4] Gonzales, R.; Ashrafizadeh, H.; Lopera, A.; Mertiny, P.; McDonald, A.: A Review of Thermal Spray Metallization of Polymer-Based Structures. In: Journal of Thermal Spray Technology 25 (2016), 5, pp. 897-919.

[5] Ganesan, A.; Yamada, M.; Fukumoto, M.: The Effect of CFRP Surface Treatment on the Splat Morphology and Coating Adhesion Strength. In: Journal of Thermal Spray Technology 23 (2014), 1-2, pp. 236-244.

[6] DIN EN ISO 14917: Thermisches Spritzen - Begriffe, Einteilung, 2017.

[7] DIN EN ISO 14916: Thermisches Spritzen - Ermittlung der Haftzugfestigkeit, 2017. 